\title{
PERKEMBANGAN KARAKTER ANNISA DALAM NOVEL PEREMPUAN BERKALUNG SORBAN KARYA ABIDAH EL KHALIEQY
}

\author{
Nazriani \\ Program Studi Pendidikan Bahasa dan Sastra Indonesia, \\ Fakultas Keguruan dan Ilmu Pendidikan, \\ Universitas Muhammadiyah Buton, Jl. Betoambari No. 36 Baubau. \\ E-mail:nazriani23@yahoo.com
}

\begin{abstract}
Abstrak
Tujuan penelitian ini untuk mengatahui perkembangan karakter Annisa dalan novel Perempuan Bekalung Sorban karya Abidah El Khalieqy. Jenis Penelitian ini merupakan penelitian kepustakaan dengan menggunakan metode deskriptif kualitatif. Data dalam penelitian ini akan dianalisis dengan menggunakan pendekatan psikologi yakni dengan mengacu pada teori kepribadian milik Sigmund Freud. Hasil penelitian ini diperoleh informasi bahwa perkembangan karakter Annisa dari kecil hingga dewasa selain didominasi oleh unsur ego maka karakter Annisa juga berkembang karena lingkungan sosialnya juga berubah. Proseses perkembangan karakter tersebut yang membentuk pribadi Annisa menjadi seorang muslimah yang tegar dan kuat, layaknya seorang wanita dewasa yang sempurna.
\end{abstract}

Kata kunci: psikologi, karya sastra, novel.

\begin{abstract}
This research was aimed to know the development of Annisa's character in Perempuan Berkalung Serban novel created by Abidah El Khalieqy. It was library research by using descriptive qualitative method. The data in this research was analyzed by using pshychology approachment, which refered to Sigmund Freud's personality theory. The result of this research was the development of Annisa's character started from young until being adult was dominated by egoistic element so that Annisa's character was developing because of the social alteration. The process of development Annisa's character made her to be rigid and strong, as a Muslim and perfect adult woman.
\end{abstract}

Key words: Psychology, literature, novel. 


\section{SANG PENCERAH}

Volume 2, Nomor 1, Februari 2016, Hlm. 54 -62

Nazriani: Perkembangan Karakter Annisa dalam Novel ...

\section{Pendahuluan}

Karya sastra lahir dari masyarakat sebagai cipta, karsa dan rasa penciptanya. Karya sastra merupakan wujud dari kehidupan di sekelilingnya dengan menggunakan media bahasa. Sastra selalu menjadi bagian dari pengalaman hidup manusia, baik aspek manusia yang memanfaatkannya bagi pengalaman hidupnya maupun dari aspek penciptaanya, yang mengekspresikan pengalaman batinnya ke dalam karya sastra. Sastra pada dasarnya merupakan refleksi kehidupan manusia, maka tepat ungkapan bahwa memahami karya sastra sama dengan memahami kehidupan manusia. Sastra tidak hanya dinilai sebagai suatu karya yang bersifat imajinatif, tetapi juga dianggap sebagai suatu karya yang kreatif dan bermanfaat sebagai konsumsi intelektual pembaca. Selain itu sastra juga mengandung unsur keindahan yang menumbuhkan rasa senang, nikmat, terharu menarik perhatian dan menyegarkan perasaan para penikmatnya. Karya sastra mampu membangkitkan perasaan senang, sedih, marah, benci, dan dendam yang diwujudkan oleh tingkah laku dan perasaan tokohtokohnya.

Sejalan dengan itu Nurgiyantoro (2005:2) menyatakan bahwa sekalipun bersifat imajiner karya sastra menawarkan berbagai permasalahan manusia dan kemanusiaan, hidup dan kehidupan yang semuanya menjadi sumber inspirasi pengarang. Karya sastra juga menceritakan berbagai masalah kehidupan dalam interaksinya dengan lingkungan dan sesama interaksinya dengan diri sendiri, serta interaksinya dengan Tuhan. Di antara sekian banyak karya sastra yang meningkat perkembangannya dan sering menjadi objek studi penelitian adalah novel. Novel yang merupakan salah satu jenis karya sastra yang diciptakan oleh pengarangnya dengan harapan untuk dapat dinikmati, dipahami, direnungkan dan dimanfaatkan oleh pembacanya. Novel yang merupakan jagad realita di dalamnya terjadi peristiwa dan perilaku yang dialami dan diperbuat manusia (tokoh). Secara spesifik realita psikologi sebagai misal, adalah kehadiran fenomenal kejiwaan tertentu yang dialami oleh tokoh utama ketika merespon atau bereaksi terhadap diri dan lingkungannya. Pada dasarnya isi sebuah karya sastra memuat perilaku manusia melalui karakter tokoh-tokoh cerita. Sangat beragam perilaku manusia yang bisa dimuat dalam cerita. Kadang-kadang hlm. ini terjadi perulangan jika diamati secara cermat. Pola atau keterulangan inilah yang ditaangkap sebagai fenomena dan seterusnya diklasifikasikan ke dalam kategori tertentu seperti gejala kejiwaan, sosial, dan masyarakat.

Tampilnya tokoh-tokoh dalam karya sastra khususnya novel yang membawa watak yang berbeda-beda, menimbulkan berbagai macam peristiwa dalam rangkaian alur cerita. Adanya peristiwa-peristiwa yang timbul akibat perbedaan-perbedaan masingmasing tokoh dalam sebuah novel menyebabkan perubahan sikap dalam diri para tokoh. Di antara karya novel yang bermutu dan dapat memperkaya pandangan pembaca serta menambah wawasan hidup serta pengalaman batin adalah karya-karya Abidah El Khalieqy dengan novel yang berjudul Perempuan Berkalung Sorban. Novel yang memiliki energi spritual yang tinggi, menggambarkan perjuangan kemanusiaan dalam ranah agama dan budaya Indonesia yang menawarkan paradigma baru yang lebih substansial untuk menempatkan idealitas perempuan dalam pandangan Islam.

Novel Perempuan Berkalung Sorban karya Abidah El Khalieqy, yang berlatar sebuah pesantren di Jawa, mengisahkan seorang perempuan bernama Annisa, yang semasa kecilnya hidup dalam budaya pesantren yang didirikan oleh ayahnya. Pesantren ini adalah pesantren yang kaku dan kolot. Dia tidak mau menerima buku- 


\section{SANG PENCERAH}

Volume 2, Nomor 1, Februari 2016, Hlm. 54 -62

\section{Nazriani: Perkembangan Karakter Annisa dalam Novel ...}

buku modern karena dianggap merusak aqidah. Para santri termasuk Annisa diajak menjadi seorang perempuan muslim. Seorang muslimah yang baik menurut agama adalah tidak boleh membantah suami, haram meminta cerai suami, serta ikhlas menerima kekurangan dan kelebihan suami, termasuk jika suami berkehendak melakukan poligami, serta tidak boleh berkata keras dari suami. Pelajaran itu membuat Annisa beranggapan bahwa pesantren sangat membela laki-laki. Ajaran pesantren meletakan perempuan sangat lemah dan tidak seimbang. Sejak kecil Annisa selalu mendapat perlakuan tidak adil dari keluarganya. Annisa selalu merasa dirinya berada dalam situasi yang salah. Hanya Khudori paman dari pihak ibu yang selalu menemani Annisa, ia selalu menghibur dan sekaligus menyajikan dunia lain bagi Annisa. Khudori menjadi curahan hati Annisa setiap kali ia merasa kesal pada keluarganya. Diam-diam mereka saling menyintai. Namun takdir berkendak lain menginjak usia remaja Annisa dinikahkan dengan Samsuddin anak seorang kiai sahabat ayahnya.

Novel Perempuan Berkalung Sorban karya Abidah El Khalieqy ini sangat menarik bila dikaji dengan pendekatan psikologi khususnya dalam analisis perkembangan karakter tokoh utamanya (Annisa). Dari masa kanak-kanak hingga dewasa dan berumah tangga Annisa banyak mengalami konflik atau tekanan yang menyebabkan perkembangan kepribadian atau karakternya. Untuk menemukan perkembangan karakter tokoh dalam novel yang paling tepat digunakan adalah pendekatan psikologi yakni dengan menggunakan teori kepribadian Sigmund Freud. Aspek psikologis selalu berkaitan dengan sifat atau karakter manusia. Manusia banyak dikuasai oleh alam batinnya sendiri, sehingga manusia selalu berada dalam keadaan berperang dengan diri, resah, dan tertekan sewaktu merasakan ketidak seimbangan dalam hidupnya atau bahkan sebaliknya manusia dalam menghadapi batinnya ia menghadapinya dengan tenang, ceria, serta arif dan bijaksana. Hlm. ini dapat merangsang peneliti untuk melakukan penjelajahan ke dalam batin atau kejiwaan untuk mengetahui lebih jauh tentang selukbeluk manusia yang beraneka ragam. Berdasarkan deskripsi di atas maka fokus penelitian ini adalah bagaimana perkembangan karakter Annisa dalam novel Perempuan Berkalung Sorban karya Abidah El Khalieqy?

Tujuan yang ingin dicapai dalam penelitian ini adalah untuk mendeskripsikan perkembangan karakter Annisa dalam novel Perempuan Berkalung Sorban karya Abidah El Khalieqy.

\section{Metode Penelitian}

Metode yang digunakan dalam penelitian ini adalah metode deskriptif kualitatif yang bertujuan untuk mendeskripsikan perkembangan karakter Annisa dalam novel Perempuan Berkalung Sorban karya Abidah El Khalieqy. Jenis penelitian yang digunakan adalah penelitian kepustakaan (library research). Sumber data dalam penelitian ini adalah data tertulis yang diperoleh melalui teks novel Perempuan Berkalung Sorban karya Abidah El Khalieqy, yang diterbitkan oleh Arti Bumi Intaran, cetakan III, Januari 2009, sebanyak 320 hlm.aman.

\section{Pembahasan}

\section{Perkembangan Karakter Tokoh Annisa}

Penelitian ini akan menganalisis tentang perkembangan karakter Annisa. Annisa adalah tokoh protagonis yang mengalami perkembangan karakter. Sesuai dengan arti namanya Annisa yang berarti perempuan yang berakal, atau perempuan yang berpandangan luas. Dalam novel ini 


\section{SANG PENCERAH}

Volume 2, Nomor 1, Februari 2016, Hlm. 54 -62

\section{Nazriani: Perkembangan Karakter Annisa dalam Novel ...}

Annisa memiliki kepribadian pembangkang dan keras kepala dan suka melawan perkataan orang tuanya. Hlm. ini terlihat ketika ia masih kanak-kanak. Perhatikan kutipan berikut.

"Siapa yang mau belajar naik kuda? Kau, bocah wedhok?"

"Iya. Memangnya kenapa, Pak? Tidak boleh? Kak Rizal juga belajar naik kuda."

"... Kau ini anak perempuan Nisa. Nggak pantas, anak perempuan kok naik kuda, pancilikan, apalagi keluyuran mengelilingi ladang. Memalukan! Kau ini sudah besar masih bodoh juga, hehh!!" Tasbih bapak bergerak lamban, mengenai kepalaku" (hlm. 8)

Karakter Annisa yang pembangkang itu juga telihat ketika kedapatan untuk kedua kalinya belajar berkuda. Perhatikan kutipan berikut.

"Kemari kau bocah bandel! Bentak bapakku

"Sekarang coba jelaskan pada Bapak, kamu kemana saja, dan apa saja yang kau lakukan sepulang sekolah. Ayo, jangan coba-coba berkata bohong?"

"E...tapi...Nisa tidak salah!

"Apanya yang tidak salah! Ngomong yang jelas! Jelas...runtut...satu persatu. Paham? Kenapa diam, kenapa tak kau ceritakan kehebatanmu naik kuda. Apa begitu yang diajarkan Bapak dan Ibumu selama ini. Kau ini anak perempuan. Mau jadi pahlawan ya? Pencilikan, pethakilan! Kau ini sadar, kau ini anak siapa, hah! Sekarang dengar! Mulai hari ini, kau tidak boleh ke luar rumah selain ke sekolah dan ke pondok. Jika sekali ketahuan membangkang, Bapak akan kunci kamu di dalam kamar selama seminggu. Paham! Anak bandel seperti ini jangan dilulu, nanti kebablasan. Ngelunjak" (hlm. 33-34)

Karakter Annisa yang pembangkang itu karena ia dipengaruhi oleh unsur id dan ego. Unsur id bekerja menurut prinsip kesenangan, tujuannya pemenuhan keinginan atau kepuasan segera. Id sangat berperan dalam pembentukan karakter. Id terlihat ketika Annisa sering mendengar cerita-cerita dari Khudori tentang perempuan kembang peradaban, yang berani memimpin pasukan perang. Annisa sering menghayal tentang mereka yang akhirnya menjadi obsesi atau keinginan yang kuat untuk menjadi seperti mereka walaupun melawan larangan orang tua. Perhatikan kutipan berikut.

"Keinginan itu terus menggedor pintu yang disekat oleh batasan-btasan di ruang hatiku. Kubayangkan kembali kisah Lek Khudori tentang Hindun binti Ataba, yang mahir naik kuda dan menderap kian kemari di padang pertempuran. Ketika bayanganku sampai pada putri Budur, yang memimpin pasukan Raja Kamaruzzaman, dan para lelaki perkasa yang membeo seperti anak ayam di belakang ekor induknya, tak sadar aku menggumam apapun yang terjadi...aku harus bias. Aku mesti belajar naik kuda. Aku tetap akan belajar naik kuda. Naik kuda" (hlm. 8)

Untuk mewujudkan keinginannya itu Annisa mencuri-curi waktu untuk ke luar bersama Khudori untuk berkuda.

" ketika Reza dan Wildan sedang menikmati mimpi di siang bolong, aku pergi mengendap ke kamar Lek Khudori dan mengajaknya untuk latihan naik kuda....aku selalu berhasil membujuknya" (hlm. 25)

Pada kutipan ini Id memaksa ego untuk memenuhi kebutuhan pemuasan dengan segera. Karena tak menuruti perkataan bapak ia dianggap anak yang pembangkang. Annisa dipengaruhi oleh unsure Id karena dia ingin lepas dari konflik dan penderitaannya yaitu tidak bebas bermain seperti kedua saudaranya. Usia yang masih terlalu muda dan keinginan untuk bebas melakukan apa saja yang dia inginkan, hlm. ini jelas pada pernyataan annisa sebagai berikut.

"Setelah kepergian Lek Khudori, aku sering mengurung diri di kamar. Teriakan Rizal 


\section{SANG PENCERAH}

Volume 2, Nomor 1, Februari 2016, Hlm. 54 -62

\section{Nazriani: Perkembangan Karakter Annisa dalam Novel ...}

tak merasuk apalagi bergema di telinga. Omelan ibu dan kebiasaan bapak untuk memarahiku seakan sudah berubah menjadi angina lalu. Masuk telinga kiri ke luar telinga kanan. Kadang juga terasa kabur kata-katanya. Tapi lek Khudori masih saja menempel di bola mataku. Satu-satunya yang tergambar dengan jelas dalam khlayanku hanyalah wajahya, kelembutannya, kecerdasannya, dan kepandaiannya. Bahkan suara lembutnya, selalu mengiang dan menyanyi-nyanyi di telingaku" (hlm. 53).

Pada kutipan di atas Annisa membayangkan hal-hal yang membuatnya senang dan nyaman dan membuang hal-hal yang menyakitkan baginya, hlm. ini merupakan kerja Id yaitu membayangkan hal-hal yang menyenangkan dan berusaha membuang hal-hal yang menyakitkan. Selain itu Annisa ingin dianggap sebagai seorang perempuan muslim yang berani, cerdas dan tidak diremehkan. Namun hlm. itu sulit baginya karena sulit mengubah persepsi lingkungannya (pesantren) dan orang-orang yang berpikiran kolot menurutnya, Annisa menginginkan agar dirinya mendapat kebebasan dalam menuntut ilmu serta menentukan pilihan hidupnya namun lagi-lagi hlm. itu sulit baginya karena Annisa hanya dianggap sebagai perempuan biasa saja, ia dipaksa kerja di dapur, tidak dibolehkan sekolah tinggi dan dinikahkan tanpa meminta persetujuannya

Karena selalu diremehkan oleh kedua kakaknya hanya karena dia seorang perempuan yang tidak perlu sekolah tinggi. Annisa berusaha untuk membuktikan kepada kedua kakakya, orang tuanya dan lingkungannya, Annisa menjadi sosok yang cerdas. Karakter yang cerdas ini karena Annisa dipengaruhi oleh Ego. Ego memegang prinsip dan selalu memandang hidup sesuai dengan realitas. Tahap ego ini mulai berkembang seiring dengan kedewasaan seseorang. Perhatikan kutipan berikut.

"Kini aku telah menerima raport dari kelas lima tanpa satu angka pun yang berwarna merah. Bahkan, peringkat rangkingku paling atas dan itu semua berkat dorongan melalui surat-surat lek Khodori yang menggemuruh penuh cita-cita." (hlm. 56)

"Menurut lek Khudori, satu-satunya cara agar aku tetap bangkit adalah terus belajar dan belajar. Melanjutkan sekolah sampai sarjana. Dan nasehat itulah yang pada saat ini harus kuperjuangkan." (hlm. 112)

Pada kutipan di atas, Annisa berpikir realistis bahwa semua impian dapat terwujud dengan memperoleh ilmu yang tinggi bagaimanapun itu caranya. Tergambar pula pada tekad Annisa alam kutipan di bawah ini:

"Aku tidak mau menjadi budak. Pun masa depan yang kerontang bukanlah impianku, juga impain siapapun" (hlm. 85)

"Niat dan usaha kerasku telah menyatu dalam diriku. Aku berhasil dan diterima pada salah satu perguruan tinggi. Aku pilih filsafat sebagai pilihan ilmu yang ingin kudalami, dengan kuliah, aku menaiki jenjang pendidikan setapak demi setapak ilmu yang merasuki otak. Membentuk pola pikir dan kepribadianku. Dengan organisasi aku mempelajari cara berdebat, berpidato dan manajemen kata untuk menguasai massa, juga lobby dengan banyak orang yang lebih lama kuliahnya... Lengkaplah jam demi jam kulalui dalam keterpesonaan ilmu dan kehausanku untuk mendalami segala sesuatu"(hlm. 202-203).

Pada kutipan di atas anisa tidak hanya memperoleh ilmu dari sekolah dasar di kampung dan dari pesantren tetapi juga di perguruan tinggi, hlm. Ini karena Annisa berpikir tentang masa depannya bila ia memperoleh ilmu dari mana saja tidak hanya dari pesantren maka akan membawa perubahan dalam hidupnya. Kutipankutipan di atas menunjukan bahwa Annisa 


\section{SANG PENCERAH}

Volume 2, Nomor 1, Februari 2016, Hlm. 54 -62

\section{Nazriani: Perkembangan Karakter Annisa dalam Novel ...}

sudah berpikir real tentang kehidupannya. Annisa juga berpikir tentang masa depannya kalau dia terus menerus hidup di lingkungan yang tak memberinya kebebasan. Dia mempunyai masa depan yang harus diperjuangkan. Annisa dibesarkan dalam lingkungan puritan yang memegang teguh agama dengan cara yang ekstrim sebagai perempuan yang cerdas, ia merasakan diskriminasi gender yng membuat jiwanya berontak. Karena jiwanya yang berontak itu ia menjadi muslimah yang kritis dan idealis. Pada tahap ini Annisa dipengaruhi oleh unsur ego namun sekalikali unsur Id juga hadir karena ego hadir karena pemaksaan dari Id. Perhatikan kutipan berikut.

"....Jika aku ke kantor, semua orang melihatku dengan hormat, tidak menutup hidung jika aku lewat seperti mereka menutup hidung dekat lek sumi, karena bau bawang dan terasi. Dan akhir bulan aku menerima gaji" (hlm. 15).

Pada kutipan di atas Annisa berpikir realis ia jelas menginginkan kehidupan yang lebih baik, ia ingin bekerja di kantor karena akan menjamin masa depannya. Hlm. Tersebut tergambar pula pada percakapannya dengan mbak May seperti pada kutipan berikut:

"Apa benar, Mbak May? Jika sekarang Nisa belajar mencuci, menyapu, memasak, apa masa depan Nisa terjamin? Dan jika Wildan dan Rizal enak-enakan tidur di kamar, apa masa depan mereka juga terjamin?" (hlm. 21).

Pertanyaan Annisa pada May itu karena Annisa berpikir bahwa tidak ada yang bisa menjamin kehidupan yang lebih baik tanpa ilmu yang tinggi, dan kenyataan yang ia lihat di lingkungannya semua perempuan hanya dididik dan dijarkan untuk menjadi perempun yang hanya tahu mengurus dan melayani suami. Tak hanya itu kritik Annisa terhadap beberapa hadis yang dianggap misioginis atau membenci perempuan ia ungkapkan sebagai pemberontakan. Dalam hlm. Ini ego yang memegang prisip realis artinya, ego memenuhi kebutuhan organisme berdasarkan objek-objek yang sesuai dan dapat ditemukan dalam kenyataan. Ego mempresentasikan kenyataan, dan sampai tingkat tertentu, juga mempresentasikan akal. Perhatikan kutipan berikut.

"Jika perempuan sedang menstruasi, mereka diharamkan menunaikan ibadah seperi shlm.at dan puasa. Maka berkuranglah agamanya. Tak peduli keharamanibadah mereka itu juga datang dan atas kemauan Allah. Dengan demikian, tidak melakukan shlm.at atau puasa di saat menstruasi adalah dalam rangka mentaati perintah allah juga, tetapi semua itu dipandang sebagai bukti kkurang agamanya. Jadi mentaati perintah Allah bagi perempuan sama dengan kurang agamanya, Tetapi bukan hanya itu. Perempuan sedang menstruasi juga dilarang masuk masjid. Padahlm. Wak Tompel, yang setiap malam minum tuak di kedai tidak dilarang untuk tidur menggelosor di dalam masjid dan tak seorangpun berani mengatakan bahwa itu haram" (hlm. 73-74).

"Apabila seorang perempuan berkata kepada suaminya. Ceraikanlah akku! Maka ia akan dating pada hari kiamat nanti dengan muka tidak berdaging, lidahnya ke luar dari kuduknya dan terjungkir di kerak jalanan. Sekalipun siang hari dia berpuasa dan malam hari bangun shlm.at selamanya"(hlm. 76).

Pada kutipan di atas Annisa mencoba mengaitkan antara hadis yang ia ketahui dengan kenyataan yang terjadi. Annisa berpikir realistis dan realis. Seperti diperkuat oleh debatnya dengan kiai Ali dalam kutipan-kutipan berikut:

"Perempuan mana saja yang diajak suaminya untuk berjimak lalu ia menundanunda hingga suaminya tertidur, amak ia akan di laknat oleh Allah, perempuan mana saja yang cemberut di hadapan suaminya, 


\section{SANG PENCERAH}

Volume 2, Nomor 1, Februari 2016, Hlm. 54 -62

Nazriani: Perkembangan Karakter Annisa dalam Novel ...

maka dia dimurkai aAllah sampai ia dapat menimbulkan senyum suaminya dan meminta keridlaanya."

"Bagaimana jika istrinya yang mengajak ke tempat tidur dan suami menunda-nunda hingga isteri tertidur, apa suami juga dilaknat oleh Allah, Pak kiai?"

"Bagaimana jika kenyataannya ada seorang istri yang terbuka dan mengajak terlebih dahulu dan tidak suka bersikap menunggu." "Bagaimana kalu suami tidak pernah berkenan karena sudah puas dengan dirinya sendiri atau berselingkuh misalnya?"

Pada kutipan di atas Annisa mengaitkan antara hadis yang ia peroleh dari pesantren dan pemikiran dirinya yang berdasarkan kenyataan. Pada tahap ini ego masih mempunyai peranan besar dalam dirinya, pengaruh ego yang kuat dalam diri Annisa terus berkembang semakin menguatkan karakternya. Selain itu Aninsa memiliki karakter penyabar. Karakter yang penyabar ini karena Annisa dipengaruhi oleh unsure super ego. Superego adalah kekuatan moral dan etik dari kepribadian, yang memakai prinsip idealistic sebagai lawan dari unsure kepuasan Id dan prinsip realistic dari Ego. Superego pada hakikatnya merupkan elemen yang mewakili nilai-nilai orang tua atau interpretasi orang tua menangani standar sosial, yang diajarkan kepada anak melalui berbagai larangan dan perintah. Apapun tingkah laku yang dilarang, dianggap salah dan dihikum oleh orang tua, akan diterima sebagai suara hati. Karakter yang penyabar ini mulai terlihat ketika ia harus menerima kenyataan di lingkungannya bahwa kaum lelaki harus lebih dominan dari kaum perempuan dalam segala hlm., misalnya tidak dibolehkan sekolah tinggi, dan tidak boleh melakukan pekerjaan yang dilakukan oleh lelaki, kaum perempuan hanya bertugas mengurus dan melayani suaminya. Bukan hanya itu ketika dirinya dinomor duakan dalam keluarganya, bapaknya hanya memgutamakan kedua kakaknya. Karena lingkungan ini (pesantren dan budaya) masih mengaggap perempuan tidak lebih dari laki-laki. Mau tidak mau sebagai bagian dari lingkungan Annisa harus mengikuti aturan yang diterapkan apalagi dirinya adalah anak seorang kiai.

Selain itu karakter yang sabar itu terlihat juga ketika ia harus dipaksa menikah dengan Samsuddin, ia tidak mempunyai kebebasan untuk menentukan pilihannya. Dalam kasus ini Annisa dipengaruhi oleh superego yang harus menuruti aturan dari orang tuanya karena memegang moralitas. Annisa harus mentaati aturan, nilai dan adat istiadat yang berlaku di lingkungannya terlihat ketika Annisa telah menjadi seorang janda dan sering jalan berdua dengan Lek Khudori yang akhirnya menimbulkan fitnah di tengah-tengah masyarakat apalagi ia anak seorang kiai, maka tidak pantas hlm. itu dilakukannya. Untuk menghindari fitnah yang lebih kejam lagi, ia melanjutkan sekolah ke Yogyakarta sementara Khudori kembali ke kampong hlm.amannya.

Dari uraian-uraian perkembangan karakter Annisa di atas dapat kita ketahui bahwa unsur Ego mempunyai peranan penting dalam pembentukan karakter individu. Walaupun insur id dan super ego juga saling mempengaruhi tetapi unsur egolah yang lebih dominan dalam diri Annisa. Seba ego bekerja sesuai dengan realitas yang ada. Selain tokoh utama dalam novel ini juga terdapat tokoh-tokoh tambahan. Tokoh-tokoh ini akan turut meramaikan cerita serta konflik dalam cerita dengan tujuan agar lebih menarik. Selain itu tokoh-tokoh ini akan memperjelas karakter tokoh utama. Tokoh-tokoh itu antara lain Samsuddin, lek Khudori, Reza, Wildan, kiai Hanan, Hj. Muthmainah, mbak May, mbak Maryam dan kiai Ali.

Dari uaraian di atas maka dapat diketahui bahwa perkembangan Annisa bersifat progesif (maju) serta bersifat dinamis. Perkembangan karakter Annisa itu karena faktor dari dalam dirinya yakni ego 


\section{SANG PENCERAH}

Volume 2, Nomor 1, Februari 2016, Hlm. 54 -62

\section{Nazriani: Perkembangan Karakter Annisa dalam Novel ...}

yang memegang prinsip relitas serta lingkungan termasuk tokoh-tokoh yang ada disekitanya. Terlihat pula pada penjelasan di atas bagaimana lingkungan Annisa yang berubah yang secara langsung membuat karakter Annisa berubah atau berkembang pula secara dinamis.

\section{Simpulan}

Simpulan penelitian ini bahwa perkembangan karakter pada tokoh Annisa dalam novel Perempuan Berkalung Sorban karya Abidah El Khalieqy bahwa dari kecil hingga dewasa Annisa memiliki karakter yang keras kepala, cerdas, kritis, sabar, kuat, dan tegar disebabkan karena lingkungan yang ditempatinya berubah-ubah yang membuat karakternya juga berubah atau berkembang serta unsur dari dalam diri Annisa yakni unsur ego yang memegang prinsip realis yang dominan dalam dirinya. Berdasarkan perkembangan karakternya dari awal hingga akhir, tokoh Annisa dapat dikatakan sebagai tokoh yang berkarakter dinamis dan bersifat progesif (maju). Tampak pada perkembangan karakternya yang semakin kuat dan tegar ketika ia harus bercerai dengan suami pertamanya dan akhirnya ditinggal mati pula oleh suami keduanya, sehingga bisa terbentuk kepribadian yang dinamis pula layaknya seorang wanita dewasa yang matang dan sempurna.

\section{Daftar Pustaka}

Albin, Rachelle Semmel. 1986. Emosi, bagaimana mengenal, Menerima, dan mengarahkannya. Yogyakarta: Kanisius.

Asrori, Mohammad \& Mohammad Ali. 2004. Psikologi Remaja. Jakarta: Bumi Aksara.
Davidoff, L. Linda. 1991. Psikologi Suatu Pengantar. Jakarta: Erlangga.

Departemen Agama R.I. 1984/1985. Psikologi Perkembangan dan Agama. Jakarta: Binbaga Islam Depag.

Endraswara, Suwardi. 2008. Metode Penelitian Psikologi Sastra. Yogyakarta: Mapress.

Esten, Mursal.1987. Kesusastraan, Pengantar, Teori \& Sejarah. Bandung: Angkasa.

Fauzi, Ahmad. 2004. Psikologi umum. Bandung : Pustaka Setia.

Fromm, Eric. 2008. Akar Kekerasan. Yogyakarata: Pustaka Pelajar Offse.

Hoed, N. Beni. 1992. Kala dalam Novel Fungsi dan Terjemahannya. Yogyakarta: Gadjah Mada University Press.

KHALIEQY, El Abidah. 2008. Perempuan Berkalung Sorban. Yogyakarta: Arti Bumi Intaran.

Nurgiyantoro. 2005. Teori Pengkajian Fiksi. Yogyakarta: Gajah Madah University Press.

Pasaribu. 1984. Teori Kepribadian. Bandung: Tarsito.

Ratna, Kutha Nyoman. 2008. Teori, Metode,dan Teknik Penelitian Sastra. Yogyakarta: Pustaka Pelajar.

Ramadhan, Tarmizi. 2009. Analisis Frustasi Tokoh Utama. http:/ / www.google.co.id/ gwt/Html. Diakses 21 Agustus, 2009.

Semi, Atar. 1993. Anatomi Sastra. Padang: Angkasa Raya.

Sujanto, Agus. 1980. Psikologi Kepribadian. Surabaya: Aksara baru. 


\section{SANG PENCERAH}

Volume 2, Nomor 1, Februari 2016, Hlm. 54 -62

Nazriani: Perkembangan Karakter Annisa dalam Novel ...

Sumardjo, Jakob, \& Saini K.M. 1997. Apresiasi Kesusastraan. Jakarta: Gramedia Pustaka Utama.

1999. Telaah Novel Indonesia. Bandung: Yayasan Adikarya IKAPI.

Tarigan, H. Guntur. 2000. Prinsip-prinsip Dasar Sastra. Bandung: Angkasa.

Wahab, Muhbib Abdul, \& Abdul Rahman Shlm.eh. 2004. Psikologi Suatu Pengantar dalam Perspektif Islam. Jakarta: Kencana.

Wahid, Sugira. 2004. Kapita Selekta Kritik Sastra. Makassar: C.V. Berkah Utami.

Walgito, Bimo. 2003. Pengantar Psikologi Umum. Yogyakarta: Andi.

Waluyo, J Herman. 1994. Pengkajian Cerita Fiksi. Surakarta: Sebelas Maret University Press.

Wellek, Rene \& Austin Waren. 1995. Teori Kesusastraan. Jakarta: PT. Gramedia.

Zaviera, Ferdinand.2008. Teori Kepribadian Sigmund Freud. Yogyakarta: Prisma Sophie.

Zulfahnur, Et.al. 1996/1997. Teori Sastra. Jakarta: Depdikbud. 